\title{
Athermal SOI ring resonators by overlaying a polymer cladding on narrowed waveguides
}

\author{
Jie Teng \\ Supervisor: Geert Morthier
}

\section{INTRODUCTION}

With mature CMOS (Complementary Metal Oxide Semiconductor) fabrication technology, silicon based devices have the potential to provide highly compact circuits with low cost, multifunctionality and enhanced performance. However, the large temperature dependence of silicon material degrades the performance of silicon-based devices $\left(\mathrm{dn} / \mathrm{dT}=1.8 \times 10^{-4} /{ }^{\circ} \mathrm{C}\right)$. To stabilize the chip temperature to a constant level, external heaters or coolers have to be employed. This element takes extra space and reduces the power efficiency of the whole chip.

In this work, we introduce a simple way to suppress the temperature dependence of silicon based devices. The wavelength temperature shift of the silicon ring resonator is reduced to less than $5 \mathrm{pm} /{ }^{\circ} \mathrm{C}$, almost 11 times lower than normal silicon waveguides.

\section{TheORETICAL ANALYSIS}

A standard SOI (silicon on insulator) structure with a height of $220 \mathrm{~nm}$ is used for designing the athermal waveguides (Figure 1). Polymer PSQ-LH with a large TO coefficient of $-2.4 \times 10^{-4} /{ }^{\circ} \mathrm{C}$ and low loss at $1550 \mathrm{~nm}$ is chosen as the cladding material. To obtain athermal silicon waveguides, the dimension of the silicon waveguide should be highly reduced to allow more light coming out of the core waveguides into polymer to

J. Teng is with Department of Information Technology Department (INTEC), Ghent University (UGent), Gent, Belgium. E-mail: Jie.Teng@UGent.be . use polymer's negative TO coefficient to counterbalance silicon's positive TO coefficient. The $\mathrm{d} \lambda_{\mathrm{m}} / \mathrm{dT}$ of standard $500 \mathrm{~nm}$ width SOI waveguides is near to $+60 \mathrm{pm} /{ }^{\circ} \mathrm{C}$. By narrowing the width of SOI waveguides, $\mathrm{d} \lambda_{\mathrm{m}} / \mathrm{dT}$ is reduced to zero and then becomes negative. From the theoretical calculation results, the ideal width for athermal silicon waveguide is around $306 \mathrm{~nm}$.

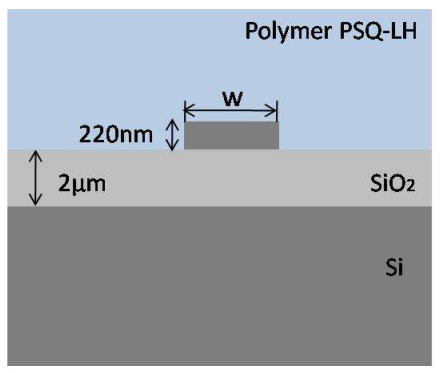

Figure 1 SOI waveguide cross-section structure

\section{FABRICATION \& MEASUREMENT RESULTS}

\section{A. Fabrication}

The narrow SOI waveguides in this paper are fabricated by deep UV lithography with standard CMOS fabrication technology. This technology offers both the required resolution and the throughput for commercial application. Simple racetrack ring resonators with different waveguide widths are fabricated as shown in Figure 2. 

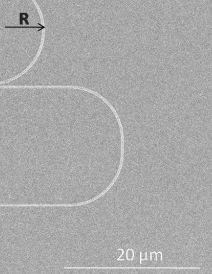

Figure 2 SEM pictures of fabricated ring resonators with a width of $350 \mathrm{~nm}$

\section{B. Measurement results}

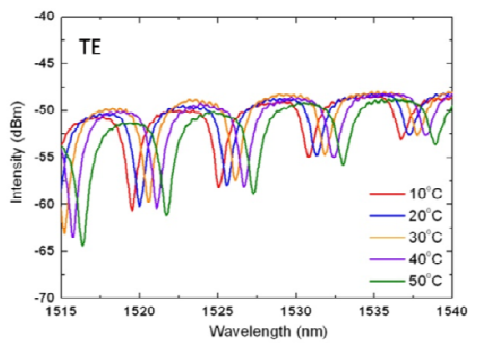

(a)

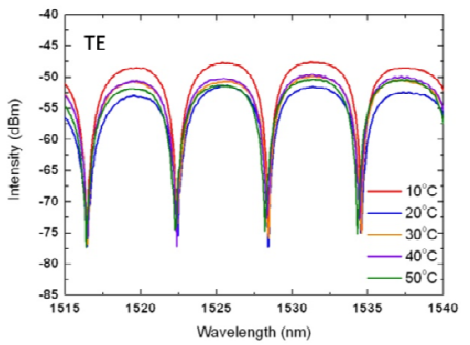

(b)

Figure 3 Transmission spectrum of a ring resonator with width of $350 \mathrm{~nm}$ at different temperatures (a) before overlaying a polymer cladding (b) after overlaying a polymer cladding $($ Width $=350 \mathrm{~nm}, \mathrm{Gap}=180 \mathrm{~nm}$, $\mathrm{L}=2 \mu \mathrm{m}, \mathrm{R}=15 \mu \mathrm{m}$ )

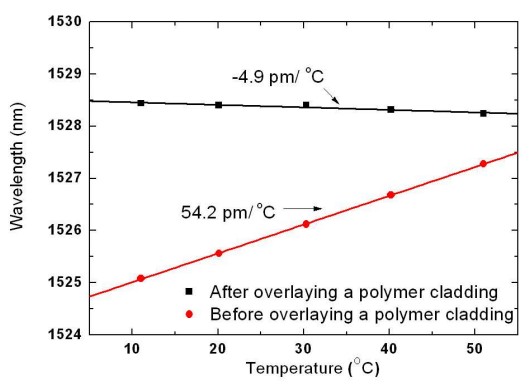

Figure 4 Linear fit of the wavelength versus temperatures

To measure the transmission spectrum at different temperatures, the sample is mounted on a heating system to accurately control the chip temperature. Figure 3 shows the measured transmission spectrum of a ring resonator (Width $=350 \mathrm{~nm}, \quad$ Gap $=180 \mathrm{~nm}$, $\mathrm{L}=2 \mu \mathrm{m}, \mathrm{R}=15 \mu \mathrm{m})$ for temperatures from $10^{\circ} \mathrm{C}$ to $50^{\circ} \mathrm{C}$ with an interval of $10^{\circ} \mathrm{C}$. By linear fitting of one resonance wavelength at different temperatures, the wavelength temperature dependence $\mathrm{d} \lambda / \mathrm{dT}$ is extracted (Figure 4). As shown in Fig.4, the wavelength temperature dependence of the $350 \mathrm{~nm}$-width ring resonator is reduced from $54.2 \mathrm{pm} /{ }^{\circ} \mathrm{C}$ to $4.9 \mathrm{pm} /{ }^{\circ} \mathrm{C}$ after overlaying a polymer PSQ-LH cladding, almost 11times than normal SOI waveguides. The ideal width for the athermal ring resonator is found to be around $350 \mathrm{~nm}$, a little different from the theoretically calculated value of $306 \mathrm{~nm}$.

\section{ACKNOWLEDGEMENTS}

The fabrication of the SOI circuits was done by CEA-LETI through ePIXfab (www.epixfab.eu). Jie Teng acknowledges CSC scholarship and Ghent University BOF cofounding. 